\title{
DELIBERATE SELF-HARM IN SUBSTANCE USE DISORDER PATIENTS-A STUDY AT TERTIARY LEVEL HOSPITALS IN BANGLADESH
}

\author{
Chowdhury $\mathrm{SH}^{1}$, Rahman $\mathrm{MS}^{2}$, Islam MA ${ }^{3}$, Tabassum $\mathrm{R}^{4}$, Kamal AHMKM ${ }^{5}$, Al-Azad MAS ${ }^{6}$, Islam $\mathrm{MM}^{7}$
}

\begin{abstract}
Introduction: Deliberate Self-harm is a term introduced to describe patients who injure themselves by self-mutilation (e.g. cutting the skin) but usually do not wish to die. Studies show that about 4 percent of all patients in psychiatric hospitals have cut themselves; the female-to-male ratio is almost 3 to 1 . Self-injury is found in about 30 percent of all abusers of oral addiction substances and 10 percent of all intravenous drug users admitted to substance-treatment units. These patients are usually in their 20 s and may be single or married. Most cut delicately, not coarsely, usually in private with a razor, blade, knife, broken glass or mirror. The wrists, arms, thighs and legs are most commonly cut; the face, breasts and abdomen are cut infrequently. Most persons who cut themselves claim to experience no pain and give reasons, such as anger at themselves or others, relief of tension and the wish to die.
\end{abstract}

Methods: It was an explorative descriptive cross sectional study aimed to explore the pattern of deliberate self harm among substance use disorder patients in three selected hospital. The research design was Quantitative in nature.

The study sites were Central Drug Addiction Treatment Centre, Dhaka; Combined Military Hospital, Dhaka Cantonment, Dhaka and Modern Psychiatric Hospital, Dhaka. The study population was Substance abusers seeking advice or getting treatment in Central Drug Addiction Treatment Centre, Dhaka; Combined Military Hospital, Dhaka Cantonment, Dhaka and Modern Psychiatric Hospital, Dhaka.

Results: The mean age of onset of taking drugs was 24 to 42 years with the $\mathrm{SD} \pm 6.83$. The range was in between 12 and 57 years and adolescents were greatly involved in self harm. Many of them used more than one substance; among them 56\% mentioned about Cannabis. Among all the respondents 52 of them reported that they use substances several times daily. Regarding the route of administration, among all the respondents, they have history of using multiple routes for administering the substances. $73 \%$ of them reported that they use substances by smoking. In this study it was revealed that, the substance users follow several methods for self harm. Among them, cutting, burning, scratching, stabbing etc are noteworthy. $39 \%$ of the substance users harmed themselves by cutting in the first episode which follows same trends in next episodes.

Conclusion: Deliberate self harm is a behavior that over the time becomes compulsive and addictive. Finding out the causes of deliberate self harm among substance related disorders will help us choose an appropriate remedy of this non-fatal but repetitive and distressing behavior which may lead

1. Maj Sohel Hasan Chowdhury, MBBS, FCPS, graded specialist in psychiatry, CMH, Bogra. 2. Brig Gen (Rtd) Md. Sajjadur Rahman, MBBS, FCPS, Ex Advisor specialist in Psychiatry, CMH, Dhaka. 3. Col Md Azizul Islam, MBBS, FCPS, FRCP, senior Psychiatrist, CMH Dhaka. 4. Dr. Royena Tabassum, MBBS, MPH (CM), Assistant Professor, Dept of community medicine, City Medical College, Gazipur. 5. Maj AHM Kazi Mostofa Kamal, MBBS, FCPS, graded specialist in Psychiatry, CMH, Rangpur. 6. Lt Col Md Abdus Samad Al-Azad, MBBS, MCPS, DFM, Asstt Prof, Forensic Medicine, AFMC, Dhaka. 7. Maj Mohammad Monirul Islam, MBBS, FCPS, Graded Spl in Psychiatry, CMH, Jessore. 
to completed suicide. Systematic mental health assessments in the emergency department of following an episode of deliberate self-harm may improve detection of mental disorders.

Key-Words: Deliberate self-harm, Substance use disorder, Compulsion and addiction.

\section{Introduction}

Deliberate self-harm (also known as self-injury) is when someone deliberately inflicts physical harm on himself/herself, usually in secret and often without anyone else knowing. Some examples are cutting, burning, biting or hitting one's body, pulling out hair or scratching and picking at sores on skin ${ }^{1}$. The most common form of self-harm is skin cutting but it also covers a wide range of behaviors including, but not limited to, burning, scratching, banging or hitting body parts, interfering with wound healing, hair pulling and the ingestion of toxic substances or objects ${ }^{2}$. "Deliberate self-harm," "self-injury," "self-mutilation," "cutting," or "non-suicidal self-injury", self-injury typically refers to a variety of behaviors in which an individual intentionally inflicts harm to his or her body for purposes not socially recognized or sanctioned and without suicidal intent ${ }^{3}$.

Para-suicide is a term introduced to describe patients who injure themselves by self-mutilation (e.g., cutting the skin), but who usually do not wish to die. Studies show that about 4 percent of all patients in psychiatric hospitals have cut themselves; the female-to-male ratio is almost 3 to 1 . The incidence of self-injury in psychiatric patients is estimated to be more than 50 times than that in the general population. Self-injury is found in about 30 percent of all abusers of oral substances and 10 percent of all intravenous users admitted to substance-treatment units. These patients are usually in their 20s and either single or married. Most cut delicately, not coarsely, usually in private with a razor, blade, knife, broken glass, or mirror. The wrists, arms, thighs and legs are most commonly cut; the face, breasts, and abdomen are cut infrequently. Most persons who cut themselves claim to experience no pain and give reasons, such as anger at themselves or others, relief of tension and the wish to die. Most are classified as having personality disorders and are

significantly more introverted, neurotic and hostile than controls. Alcohol abuse and other substance abuse are common and most cutters have attempted suicide. Self-mutilation has been viewed as localized self-destruction with mishandling of aggressive impulses caused by a person's unconscious wish to punish himself or herself or an interjected object ${ }^{4}$.

The phrases 'substance use disorder' (Diagnostic and statistical manual-IV) or disorders due to psychoactive drug use (International classifications of diseases-10) are used to refer to conditions arising from the misuse of alcohol, psychoactive drugs and other chemicals such as volatile substances. The two classification systems, DSM-IV and ICD-10, use similar categories for substance use disorders but group them in different ways. Both schemes recognize the following disorder: Intoxications, abuse (or harmful use), dependence, withdrawal states, psychotic disorder, amnesic syndromes ${ }^{5}$.

Among the social and medical illness of the twentieth century, substance abuse rank as one of the most devastating and costly. The drug problem is a major global concern including Bangladesh. Department of Narcotic Control (DNC) in Bangladesh reported in June 2008 that about 5 million drug addicts in the country $\&$ addicts spend at least 17 billion taka on drugs per year ${ }^{6}$.

Depression, substance misuse and other mental health problems are more common in people who deliberately harm themselves and the rate of suicide in the year following an episodes of deliberate self harm is some $60-100$ times than that of the general population ${ }^{7}$.

The Oxford Monitoring System for attempted suicide and patient case-notes were used to obtain information on alcohol and drug misuses assessed by the general hospital psychiatric services after deliberate self harm in 1992. Of 724 patients, $200(28 \%)$ were substance misuses (36\% of males, $23 \%$ of females $)^{8}$. 
For these reason psychiatrists need to be particularly informed about the nature of deliberate self harm and suicidal behavior and about strategies aimed at its prevention. There are many research works in these fields had been conducted in many countries but such work has never been conducted in our country and the present study will be a novel one.

\section{Materials and Method}

It was an explorative descriptive type of cross sectional study aimed to explore the pattern of deliberate self harm among substance use disorder patients in three selected hospitals. The research design was quantitative in nature. The study was carried out in three sites, viz., Central Drug Addiction Treatment Centre, Dhaka; Combined Military Hospital, Dhaka Cantonment, Dhaka and Modern psychiatric hospital, Dhaka. These are renowned tertiary level Psychiatric hospitals in Bangladesh, offering both clinical and academic services. The study was carried out from July 2009 to December 2009. Study populations were substance abusers seeking advice or getting treatment.

A consecutive series of 100 patients of Substance Use Disorder diagnosed by Qualified Psychiatrist were selected for the study. Purposive sampling method was applied. All available respondents were included who were willing to participate in the research on different working days. As per selection criteria of the study, data collection was carried out through direct contact with the respondents with the help of structured questionnaire. Oxford Pilot Complex Needs Service: Acts of deliberate self-harm inventory were also used. The respondents were given full assurance on ethical point of view that, the information given by them would not be disclosed to any unauthorized person or agency and it would be used solely for research purpose. At the end of data collection a review to detect and gather missed data was carried out. Then the codes were filled up in each completed data-sheet at the end of each working day. The collected data were entered into the computer with help of the software SPSS (Statistical Package for Social Science) for windows version 13.0. Quantitative data input was done in SPSS.

\section{Results}

The sample was taken purposefully and there were 100 patients. Among the patients, 94 (94\%) were male and $6(6 \%)$ were female and the proportion (Male: Female $=15.67: 1$ ) was due to some constraints like substance users are mostly male in Bangladesh and females users reported less due to social stigma. Regarding the educational status, 29 of them had qualification up to primary level, 8 of them were illiterate. In case of occupation, 69 $(69 \%)$ patients were either in service, business or in other employment and 18 (18\%) were unemployed. 50 of the respondents were married, 48 were unmarried and 2 were divorced.

Table- I: Socio-demographic information

\begin{tabular}{|c|c|c|}
\hline Statistics & $\mathbf{N}$ & (\%) \\
\hline $\mathbf{N}$ & 100 & $(100 \%)$ \\
\hline \multicolumn{3}{|l|}{ Sex } \\
\hline Male & 94 & $(94 \%)$ \\
\hline Female & 6 & $(6 \%)$ \\
\hline \multicolumn{3}{|l|}{ Education Status } \\
\hline Up to Primary level & 29 & $(29 \%)$ \\
\hline Up to Secondary level & 21 & $(21 \%)$ \\
\hline Up to Higher Secondary level & 21 & $(21 \%)$ \\
\hline Above Higher Secondary level & 21 & $(21 \%)$ \\
\hline Illiterate & 8 & $(8 \%)$ \\
\hline \multicolumn{3}{|l|}{ Employment Status } \\
\hline Service & 69 & $(69 \%)$ \\
\hline Unemployed & 18 & $(18 \%)$ \\
\hline Others & 13 & $(13 \%)$ \\
\hline \multicolumn{3}{|l|}{ Marital Status } \\
\hline Married & 50 & $(50 \%)$ \\
\hline Unmarried & 48 & $(48 \%)$ \\
\hline Divorced & 2 & $(2 \%)$ \\
\hline
\end{tabular}

Socio-economic condition and whereabouts of patients 
Regarding the socioeconomic condition, $51 \%$ of them were from middle class, $34 \%$ of them were from lower class and the rest $15 \%$ were from upper class. 86 of them were from urban area and the remaining 14 of them were from rural area.

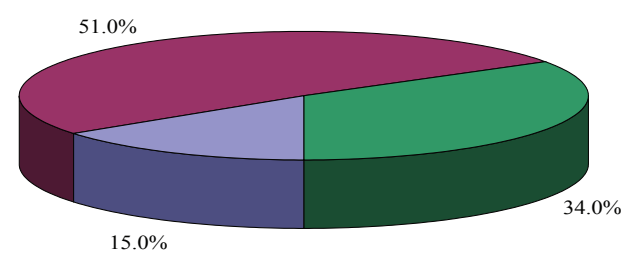

$\square$ Upper $\square$ Middle $\square$ Lower

Fig-1: Pie chart of socioeconomic condition

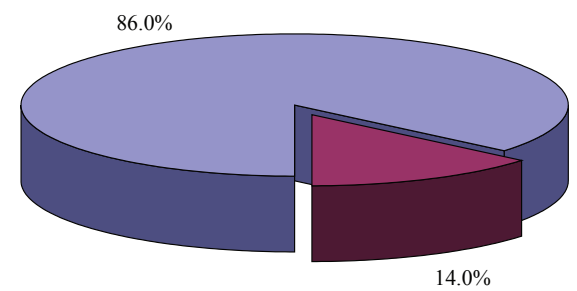

$\square$ Urban $\square$ Rural

Fig-2: Pie chart of habitat

\section{Name of substance/ substances used by the respondents}

The respondents had given multiple responses about the substances during their interview. Many of them used more than one substance. Among them 56\% mentioned about Cannabis. 


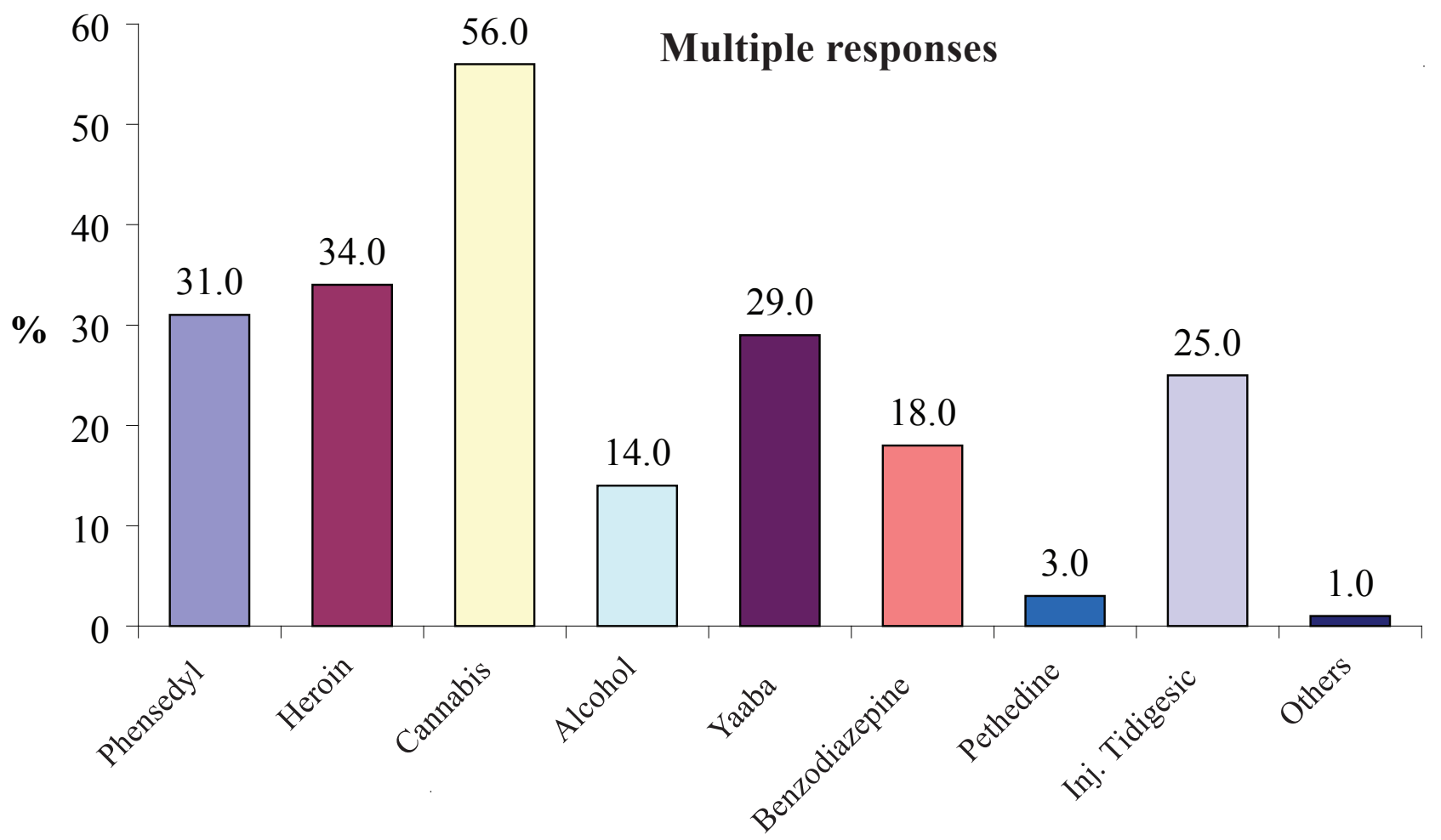

The name of substance

Fig-3: Bar diagram of the name of substance

Among all the respondents 52 of them reported that they use substances several times daily, 9 of them use substances once daily, 31 of them use substances more than 3 times in a week and the rest 8 use substances 2 to 3 times in a week. (History of last 30 days)

Table-II: Frequency of taking substance (in last 30 days)

\begin{tabular}{lcc}
\hline & Frequency & Percent \\
\hline Daily several times & 52 & 52.0 \\
Daily once & 9 & 9.0 \\
More than 3 times in a & 31 & 31.0 \\
week & & \\
2 to 3 times in a week & 8 & 8.0 \\
Total & 100 & 100.0 \\
\hline
\end{tabular}

\section{Route of administration}

Among all the respondents, they have history of using multiple routes for administering the substances. $73 \%$ of them reported that they use substances by smoking.

Multiple responses of the route of administration

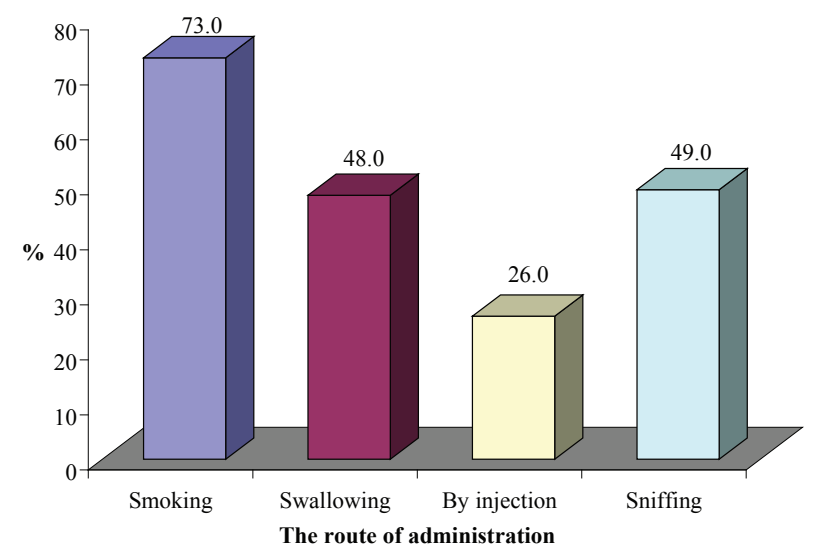

Fig-4: Bar diagram of the route of administration 


\section{Reason for initiating substance intake}

There were various reasons for the initiation of substance intake. $60 \%$ mentioned that they started it due to frustration. $43 \%$ mentioned about peer pressure and $4 \%$ mentioned interesting facts that without taking those substances, crimes like robbery, homicidal act etc may not be possible. Other had multiple responses

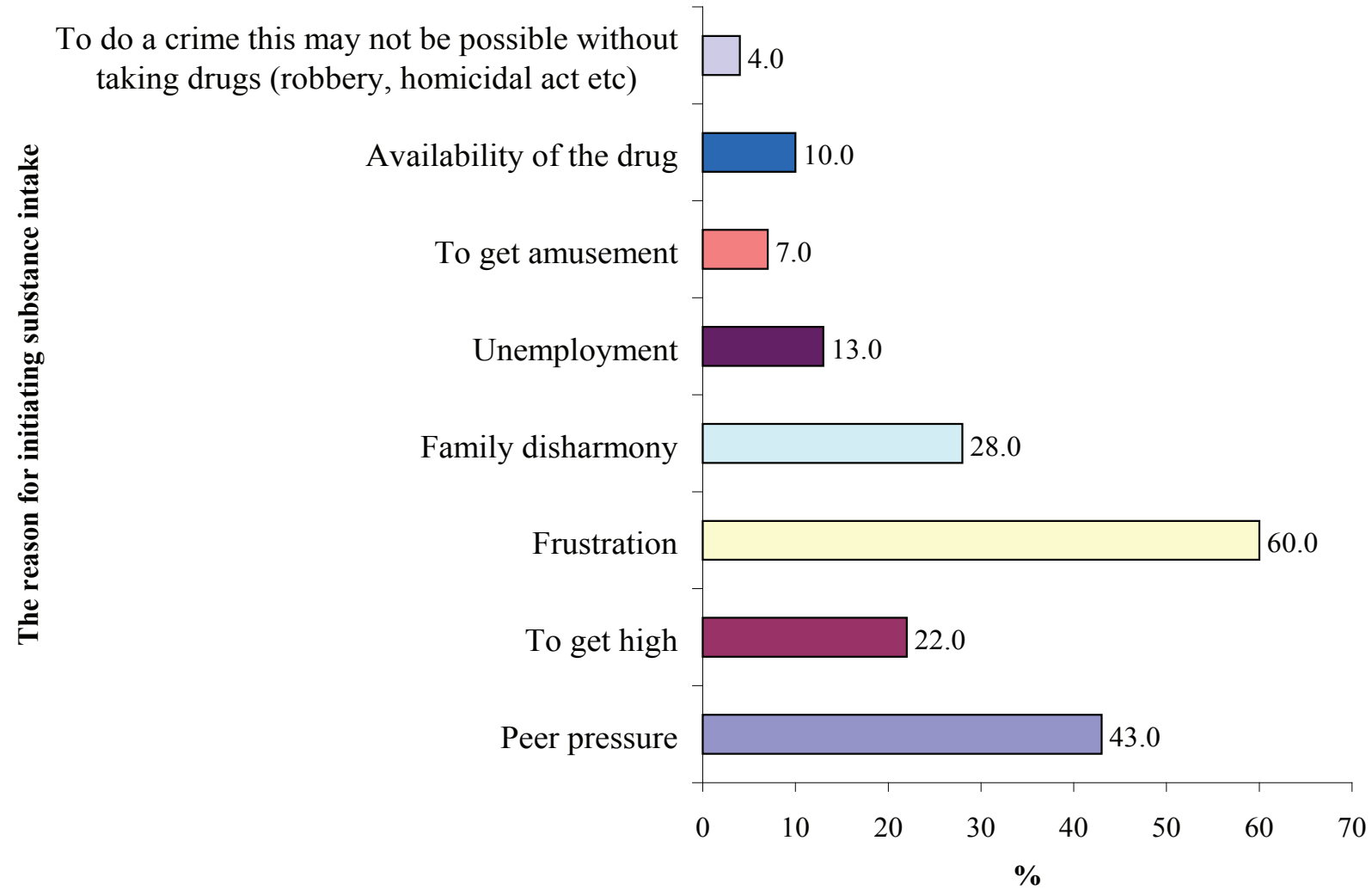

Fig-5: Bar diagram of the reason for initiating substance intake

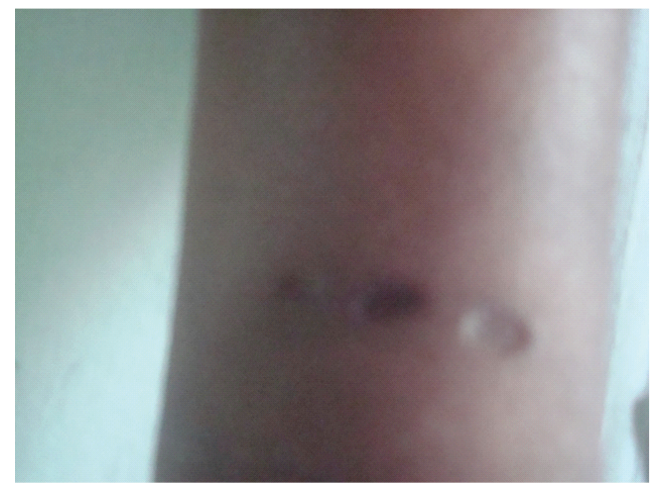

Fig-6: Burn by cigarette

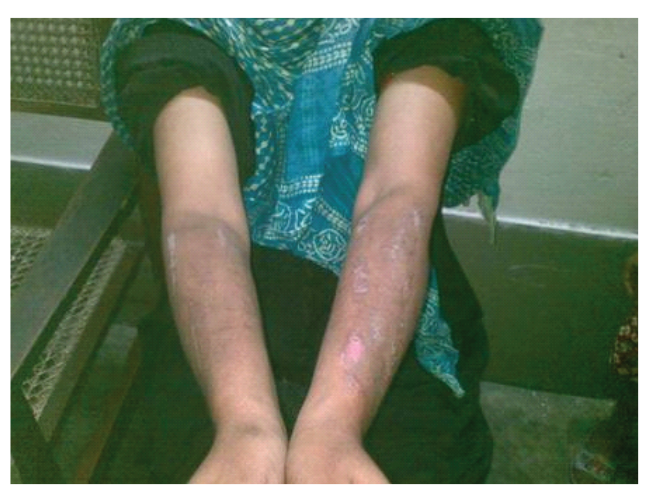

Fig-7: Scratch by sharp blade 
During interview, it was revealed that the mean age of onset of taking drugs was 24.42 years with the $\mathrm{SD} \pm 6.83$. The range was in between 12 and 57 years.

The mean time passed after using the substance was 2.77 years with the $\mathrm{SD} \pm 2.37$ and the range was 4 months to 15 years.

Table-III: Age of onset of taking drugs and time passed using those drugs

\begin{tabular}{lcc}
\hline & Mean \pm SD & Range \\
\hline The age at which you & $24.42 \pm 6.83$ & $12.00-57.00$ \\
have taken substance & & \\
first & & \\
age in years & & \\
How long you are taking & $2.77 \pm 2.37$ & $0.25-15.00$ \\
this substance/ & & \\
substances? & & \\
\end{tabular}

In this study $72 \%$ of the patients were from Central Drug Addiction Treatment Centre, which was a government organization, 9\% were from Combined Military Hospital and the rest 19\% were from Modern Psychiatric Hospital, Dhaka. Here it can be said that more people go to government hospitals.

Table -IV: Distribution of patients by hospital

\begin{tabular}{lcc}
\hline Name of the hospital & Frequency & Percent \\
\hline $\begin{array}{l}\text { Central drug addiction } \\
\text { treatment centre }\end{array}$ & 72 & 72.0 \\
$\begin{array}{l}\text { Combined Military Hospital } \\
\text { Modern psychiatric }\end{array}$ & 9 & 9.0 \\
hospital & 19 & 19.0 \\
Total & $\mathbf{1 0 0}$ & $\mathbf{1 0 0 . 0}$
\end{tabular}

In this study, it was found that those who availed the facility of private hospital, most of them were highly educated. Chi-square value $=35.13, \mathrm{df}=8$, $p$ value $=0.001$. So the $p$ value is very significant.

Table-V: Distribution of educational status of patients by hospital

\begin{tabular}{|c|c|c|c|c|c|}
\hline \multirow{4}{*}{$\begin{array}{l}\text { Educational } \\
\text { status }\end{array}$} & \multicolumn{4}{|c|}{ Name of the hospital } & \multirow[b]{4}{*}{ Total } \\
\hline & \multirow{2}{*}{\multicolumn{2}{|c|}{$\begin{array}{c}\text { Central Drug } \\
\text { Addiction }\end{array}$}} & \multirow{3}{*}{$\begin{array}{l}\text { Combined } \\
\text { Military } \\
\text { Hospital }\end{array}$} & \multirow{3}{*}{$\begin{array}{c}\text { Modern } \\
\text { Psychiatric } \\
\text { H ospital }\end{array}$} & \\
\hline & & & & & \\
\hline & Treatment C & entre & & & \\
\hline Illiterate & $8\left(\begin{array}{ll}1 & 1.1\end{array}\right)$ & $\#$ & $0(.0)$ & $0(.0)$ & $8(8.0)$ \\
\hline Primary level & $28(38.9)$ & & $0(.0)$ & $1(5.3)$ & $29(29.0)$ \\
\hline Secondary level & $16(22.2)$ & & $4(44.4)$ & $1(5.3)$ & $21(21.0)$ \\
\hline Higher Secondary level & $13(18.1)$ & & $2(22.2)$ & $6(31.6)$ & $21(21.0)$ \\
\hline Above & $7(9.7)$ & & $3(33.3)$ & $11(57.9)$ & $21(21.0)$ \\
\hline Total & $72(100.0)$ & & $9(100.0)$ & $19(100.0)$ & $100(100.0)$ \\
\hline
\end{tabular}


Chi-square value $=35.13, \mathrm{df}=8, \mathrm{p}$ value $=0.001$

The Modern Psychiatric Hospital is a modern hospital with state of the art facilities. In this study, it was found that those who availed the facility of private hospital, most of them were from higher socio economic condition. Here the value is $42.1 \%$. Chi-square value $=24.85$, $\mathrm{df}=4$, $\mathrm{p}$ value $=0.001$ which is very significant.

Table-VI: Socio-economic condition by hospital

\begin{tabular}{|c|c|c|c|c|}
\hline & \multicolumn{3}{|c|}{ Name of the hospital } & \\
\hline & Central Drug & Combined & Modern & \\
\hline Socioeconomic & Addiction & Military & Psychiatric & \\
\hline condition & Treatment Centre & Hospital & Hospital & Total \\
\hline Upper & $5(6.9)$ & $2(22.2)$ & $8(42.1)$ & $15(15.0)$ \\
\hline Middle & $34(47.2)$ & $7(77.8)$ & $10(52.6)$ & $51(51.0)$ \\
\hline Lower & $33(45.8)$ & $0(.0)$ & $1(5.3)$ & $34(34.0)$ \\
\hline Total & $72(100.0)$ & $9(100.0)$ & $19(100.0)$ & $100(100.0)$ \\
\hline
\end{tabular}

\#Figure within parentheses indicates percentage.

Chi-square value $=24.85, \mathrm{df}=4, \mathrm{p}$ value $=0.001$

It was revealed that, the substance users followed several methods for self-harm. Among them, cutting, burning, scratching, stabbing etc are noteworthy. $39 \%$ of the substance users harmed themselves by cutting in the first episode which followed same trends in next episodes. Next to that many of them harmed themselves by burning $(26 \%)$.Regarding the accuracy of harm, in $62 \%$ cases the harm was reasonably accurate in the first episode and same trend was observed in next episodes. Next to that $26 \%$ were accurate in the first episode.
Table-VII: Method and accuracy of harmed in last 12 months

\begin{tabular}{|c|c|c|c|c|}
\hline & & $\begin{array}{c}\text { First } \\
(n=100)\end{array}$ & $\begin{array}{l}\text { Second } \\
(n=32)\end{array}$ & $\begin{array}{l}\text { Third } \\
(n=4)\end{array}$ \\
\hline \multicolumn{5}{|c|}{ Method } \\
\hline$?$ & Cutting & $39(39.0)^{\#}$ & $13(40.6)$ & $3(75.0)$ \\
\hline$?$ & Burning & $26(26.0)$ & 7 (21.9) & $0(.0)$ \\
\hline$?$ & Others & $26(26.0)$ & $8(25.0)$ & $0(.0)$ \\
\hline$?$ & Scratching & $7(7.0)$ & $4(12.5)$ & $1(25.0)$ \\
\hline$?$ & Stabbing & $2(2.0)$ & $0(.0)$ & $0(.0)$ \\
\hline \multicolumn{5}{|c|}{ Accuracy } \\
\hline$?$ & Accurate & $26(26.0)$ & $4(12.5)$ & $1(25.0)$ \\
\hline$?$ & $\begin{array}{l}\text { Reasonably } \\
\text { accurate }\end{array}$ & $62(62.0)$ & $17(53.1)$ & $0(.0)$ \\
\hline$?$ & Questionable & $10(10.0)$ & $10(31.3)$ & $3(75.0)$ \\
\hline$?$ & Inaccurate & $2(2.0)$ & $1(3.1)$ & $0(.0)$ \\
\hline
\end{tabular}

\#Figure within parentheses indicates percentage. 


\section{Discussion}

In this study, 100 patients were taken for interview. Among them 96 were male and rest 4 were female. As Bangladesh is a conservative Islamic country, substance abuse is not that much common in female and same trends follow for deliberate self harm. Risk factors for subsequent

suicide were a diagnosis of substance use disorder, male gender and previous suicide attempts. The findings of this study suggest that deliberate self-harm patients have a high risk for both suicide and other causes of death. Male gender and substance use disorders are significant risk factors for both later suicide and other causes of death. Male suicide attempters with substance use disorders have remarkably high total and suicide mortality. There are also opposite findings in the study of Kaplan and Sadocks ${ }^{4}$ which show that about 4 percent of all patients in psychiatric hospitals have cut themselves; the female-to-male ratio ${ }^{9}$ is almost 3 to 1 .

In this study, we found less number of female cases that underwent deliberate self harm. Men were almost five times more likely to commit suicides than women, in all countries of the European region deliberate self-harm is more frequent among women life. Deliberate self harm was more common in females than it was in males $(11.2 \%$ v $3.2 \%$; odds ratio $3.9,95 \%$ confidence interval 3.1 to 4.9$)^{10}$. In females the factors included in a multivariate logistic regression for deliberate self harm were recent self harm by friends, self harm by family members, drug misuse, depression, anxiety, impulsivity, and low self esteem. In males the factors were suicidal behavior in friends and family members, drug use, and low self esteem ${ }^{11}$.

Regarding the age, in this study, the mean age of onset of taking drugs was 24.42 years with the SD \pm 6.83 . The range was in between 12 and 57 years. The suicide rate, however, is rising most rapidly among young persons, particularly males 15 to 24 years of age, and the rate is still rising. In all countries the risk of deliberate self-harm has been significantly elevated among adolescents who reports some or numerous episodes of intoxication, controlling for confounding factors ${ }^{11}$. The results support the assumption that intoxication is significantly related to the association between alcohol consumption and deliberate self-harm in adolescents $^{12}$.

In this study, we found that deliberate self harm was more prevalent in those having low education (Primary level, 29\%). Half of the cases were educated up to secondary level $(53 \%, \mathrm{n}=46)$.

Approximately 24\% ( $\mathrm{n}=21)$ had received tertiary education (diploma/degree), 20\% $(\mathrm{n}=17)$ had primary education, and $2 \%(\mathrm{n}=2)$ had not had formal schooling. Statistical analysis showed there was a significant difference between cases and controls $(\mathrm{p}<0.05)$; the DSH (Deliberate Self-Harm) subjects were more likely to have lower levels of education than controls ${ }^{13}$.

Regarding marital status, in this study, $50 \%$ of the respondents were married, $48 \%$ were unmarried and rest $2 \%$ was divorced. A high proportion of single patients with DSH were observed. Approximately 58\% ( $\mathrm{n}=50)$ had never been married, $1(1 \%)$ was divorced, and $1(1 \%)$ was widowed. The remaining $40 \% \quad(n=34)$ were married (Pearson Chi-square $=1.13, \mathrm{df}=1, \mathrm{p}>$ 0.05). Chi-square analysis comparing marital status among the DSH patients and controls yielded no significant difference $(\mathrm{OR}=1.4 ; 95 \%$ CI, 0.75-2.63; $p>0.05)^{14}$.

Regarding employment, in this study, $69 \%$ of the patient were either in service, business or in other employments, $18 \%$ were unemployed. Majority of the cases $(78 \%, n=67)$ were employed and $22 \%$ $(n=19)$ were not working. Analysis of employment status between cases and controls showed no significant difference $(\mathrm{OR}=1.55 ; 95 \% \quad \mathrm{CI}$, 0.78-3.09; $\mathrm{p}>0.05)$. The characteristics of individual DSH patients reflected those of the areas where they lived. The socio-economic correlates of deliberate self-harm were examined by reference both to a series of 368 patients interviewed soon after the event and to the pattern of its distribution throughout the city. A significant positive association was found with areas of 
overcrowding, lack of exclusive domestic amenities and high proportion of foreign born residents, but there was no correlation with the proportion of persons living alone or with the type of accommodation ${ }^{15}$.

In this study, we saw that substance users use several things. Many of them used more than one substance. $31 \%$ of them mentioned about Phensidyl, 34\% mentioned Heroin, 56\% mentioned Cannabis, 14\% mentioned Alcohol, $29 \%$ mentioned Tab. Yaaba, 18\% mentioned Benzodiazepine, 3\% mentioned Inj. Pethedine, $25 \%$ mentioned about Inj. Tidigesic and 1\% about other substances. The most commonly detected drugs were methadone, heroin/morphine, benzodiazepines and cannabis and, as in 2002, methadone was more frequently detected than heroin/morphine ${ }^{16}$. Those factors associated with recent suicide attempts were: benzodiazepine use, recent heroin overdose, more extensive polydrug use, female gender, younger age, less education, major depression, current suicidal ideation, Borderline Personality Disorder (BPD) and Post-Traumatic Stress Disorder ${ }^{17}$.

Regarding the frequency of taking substance/ substances (in last 30 days), among all the respondents 52 of them reported that they use substances several times daily, 9 of them use substances once daily, 31 of them use substances more than 3 times in a week and the rests 8 use substances 2 to 3 times in a week. Many of them use multiple substances simultaneously. The problems relating to alcohol use are very common among deliberate self-harm (DSH) patients, and alcohol abuse increases the risk of both DSH and suicide $^{18}$. Injecting Cocaine Users (ICU) (38\%) were significantly more likely than to have attempted suicide than non injecting cocaine user (NICUs) that they had done so on more than one occasion ( $23 \%$ vs. $3 \%$, respectively). The most common method used among both groups was self-poisoning (ICUs 28\%, NICUs $8 \%$ ), primarily by drug overdose. Violent methods had been used by $22 \%$ of ICUs and $3 \%$ of NICUs. Multivariate analyses revealed that injecting users female gender, and more extensive poly drug use were independent predictors of a suicide attempt ${ }^{19}$.

Regarding the route of administration, among all the respondents, they had history of using multiple route for administering the substances. $73 \%$ of them reported that they use substances by smoking, $48 \%$ of them used substances by swallowing, and $26 \%$ of them used substances by injecting and $49 \%$ by sniffing. Any history of injecting drugs increased the odds of being diagnosed with antisocial personality disorder by a factor of 21.01 , alcoholism by 4.42 , and unipolar depression by 3.02. A diagnosis of antisocial personality disorder increased the odds of having injected drugs by a factor of 27.19, while diagnoses of alcoholism or unipolar depression conveyed odds for injecting drugs of 4.62 and 3.70 respectively. Intravenous drug use was associated with an 8.27-fold increase in odds for a suicide attempt compared with no drug use $^{20}$.

In this study it was revealed that, the substance users followed several methods for self harm. Among them, cutting, burning, scratching stabbing etc are noteworthy. $39 \%$ of the substance user harmed themselves by cutting in the first episode which followed same trends in next episodes. Next to that many of them harmed themselves by burning (26\%). Of the adolescents reported having engaged in some kind of deliberate self-harm at least once; $41.5 \%$ reported at least one kind of self-harm more than once; and $13.8 \%$ reported at least one kind of deliberate self-harm behavior "many times". Although there were no overall gender differences in self-harm, the girls reported significantly more with cutting wrists, arms and other body areas than the boys. High rates of deliberate self-harm were associated with low self-esteem and low mindfulness ${ }^{21}$. The commonest method of DSH was an overdose of medication or ingestion of toxic substances such as insecticide, detergent, rat poison, or kerosene $(91 \%, \mathrm{n}=78)$. Two subjects $(2 \%)$ committed both self-poisoning and self-injury. Two others $(2 \%)$ swallowed pieces of glass and slashed their wrist. 
For most subjects it was their first attempt at DSH $(77 \%, \mathrm{n}=66)$ while the remaining $23 \%(\mathrm{n}=$ 20) admitted of at least one previous attempt ${ }^{22}$. A number of studies compared methods of self harm in different ethnic groups. Most of these studies collected data on methods of self harm from medical records and interviews with patients seen in hospital departments. These described the types of ingested medication, and that oral ingestion of tablets was a common method of self harm. However, there were only a few significant findings. Domestic substances, such as bleach, coal gas and medications, were used more often by South Asians than other ethnic groups; among West Indians psychotropic medications were as commonly used as analgesics. However, two studies concluded that attempted suicide by self poisoning was less prevalent in West Indian immigrants than white patients.

\section{Conclusion}

Deliberate self harm is a behavior that over time becomes compulsive and addictive. Like any other addiction, even though other people think the person should stop, most addicts have a hard time for just saying no to their behavior, even when they realize it is unhealthy. Finding out the causes of deliberate self harm among substance related disorders will help us to choose an appropriate remedy of this non-fatal but repetitive and distressing behavior which may land to complete suicide. Trends identified by research point toward the probability that, in the near future, Family Medicine and Primary Health Care Physicians are likely to see patients who injure themselves more frequently.

\section{References}

1. Retrieved from the website http://www.au.reachout.com/deliberate self harm.

2. Retrieved from the website http://www.enwikipedia.org/self harm.

3. Favazza AR. Bodies under siege: self-mutilation and body modification in culture and psychiatry, Johns Hopkins 1996; 2: 1-3.

4. Sadock BJ, Sadock VA, eds. Kaplan \& Sadock's Synopsis of Psychiatry: Behavioral
Sciences/Clinical Psychiatry. 10th ed. Lippincott Williams \& Wilkins. 2007; 34(1): 1-3.

5. Gelder M, Harrison P, Cowen P, Shorter Oxford Textbook of Psychiatry 5th edn. Oxford University Press.2006; 18: 428-9.

5. Nessa A, et al. Drug abuse and addiction, Mymensingh Med J.2008; 17(2): 227-35.

6. Heath NL, Schaub K, Holly S, Nixon MK. Self-injury today: review of population and clinical studies in adolescents. In Nixon MK,

Heath NL, eds. Self-injury in youth: the essential guide to assessment and intervention. New York. 2008; $2: 12-3$.

7. Ross S, Heath N. A study of the frequency of self-mutilation in a community sample of adolescents. J Youth Adolesc. 2002; 31:66-77.

8. Suominen K, Isometsä E, Haukka J, Lönnqvist J. Substance use and male gender as risk factors for deaths and suicide. Journal of Social Psychiatry and Psychiatric Epidemiology. 2006; 39(9) : 720-4.

9. Hawton K, Rodham K, Evans E, Weatherall R. Deliberate self harm in adolescents: self report survey in schools in England. BMJ. 2002; 325 (7374): 1207-11.

10. Retrieved from the website of EURO region of WHO http://www.euro.who.int/mentalhealth/Policies

11. Ingeborg $\mathrm{R}$, Mette $\mathrm{Y}$ et al cross-National Comparison of the association between alcohol comsumption and Deliberate Self Harm in adolescents suicide and life threatening behavior 2007; 37: 605-15.

12. Ainsah O, Norharlina B, Osman CB. The Association between Deliberate Self-harm and Menstrual Cycle among patients admitted to Hospitals in Kuala Lumpur. Hong Kong J Psychiatry 2008; 18:158-65.

13. Hawton K, Harriss L, Hodder K, Simkin S, Gunnell D. The influence of the economic and social environment on deliberate self-harm and suicide: an ecological and person-based study. Psychological Medicine 2001, 31:5:827-36.

14. Morgan H G, Pocock H, Pottle S. The urban distribution of non- fatal deliberate self-harm. The British Journal of Psychiatry 1975; 126: 319-28. 
15. Pedersen CL, Steentoft A, Kringsholm B. Death among drug addicts in Eastern Denmark, 2005.Ugeskr Laeger. 2008; 70(50):4124-7.

16. Darkes, Ross J, Lynskey M, Teesson M Attempted suicide among entrants to three treatment modalities for heroin dependence in the Australian Treatment outcome Study (ATOS): Prevalence and sick factors. Drug Alcohol Depend 2004; 73(3):315.

17. Camilla Haw et al. Alcohol dependence, excessive drinking and deliberate self-harm Trends and patterns in Oxford, 1989-2002. Journal of Social Psychiatry and Psychiatric Epidemiology 2005; 40:964-71.

18. Shane Darke and Sharlene Kaye. Attempted suicide among injecting and non injecting cocaine users in Sydney, Australia. Journal of Urban Health 2008; 81 (3): 505-15.

19. Dinwiddie $\mathrm{SH}$, Reich $\mathrm{T}$, Cloninger $\mathrm{CR}$. Psychiatric comorbidity and suicidality among intravenous drug users. J Clin Psychiatry. 1992; 53 (10): 364-9.

20. Lars-Gunner Lundh, Jessica Karim, Eva Quilisch. Deliberate self harm in 15 year old adolescent: A pilot study with modified version of the deliberate self harm inventory. Scand J Psychol. 2007; 48 (1):33-41.
21. Weiderman MW, Pryor T. Substance use and impulsive behaviors among adolescents with eating disorders. Addict Behav. 1996; 21: 269-72. 22. Bhui K, McKenzie K, Rasul F. Rates, risk factors \& methods of self harm among minority ethnic groups in the UK: a systematic review. BMC Public Health. 2007; 7:336

18. Shane Darke and Sharlene Kaye. Attempted suicide among injecting and non injecting cocaine users in Sydney, Australia. Journal of Urban Health 2008; 81 (3): 505-15.

19. Dinwiddie SH, Reich T, Cloninger CR. Psychiatric comorbidity and suicidality among intravenous drug users. J Clin Psychiatry. 1992; 53 (10): 364-9.

20. Lars-Gunner Lundh, Jessica Karim, Eva Quilisch. Deliberate self harm in 15 year old adolescent: A pilot study with modified version of the deliberate self harm inventory. Scand J Psychol. 2007; 48 (1):33-41.

21. Weiderman MW, Pryor T. Substance use and impulsive behaviors among adolescents with eating disorders. Addict Behav. 1996; 21: 269-72. 22. Bhui K, McKenzie K, Rasul F. Rates, risk factors \& methods of self harm among minority ethnic groups in the UK: a systematic review. BMC Public Health. 2007; 7:336 